\title{
AVALIAÇÃO DO DESEMPENHO ESCOLAR: VISÃO DAS PROFESSORAS DO SEGUNDO ANO DO ENSINO FUNDAMENTAL
}

\author{
Josiane Peres GONÇALVES ${ }^{1}$ \\ Tamires Ferreira AZEVEDO ${ }^{2}$
}

RESUMO: A presente pesquisa tem por finalidade investigar a opinião e prática de professores em relação à avaliação do desempenho escolar dos alunos, cuja amostra foi composta por 7 (sete) professoras que atuavam no $2^{\circ}$ ano do Ensino Fundamental de escolas municipais e estaduais de Naviraí - MS. A abordagem teórica foi norteada por autores como Libâneo, Kraemer, Haydt, entre outros, em que apresentam discussões relevantes sobre a temática, incluindo os três tipos de avaliação: diagnóstica, formativa e somativa. Para a realização da coleta de dados, foi utilizado um questionário com 15 questões abertas, sendo respondido pelas próprias professoras e entregue posteriormente para análise e sistematização. Os resultados indicaram que as professoras que fizeram parte da pesquisa reconhecem que na medida em que avaliam os seus alunos elas percebem se os seus objetivos estão sendo alcançados, sendo possível redirecionar sua prática visando atender a necessidade da turma e consequentemente contribuir com a melhor aprendizagem dos alunos. Quanto às práticas utilizadas para avaliar, elas são bem diversificadas, incluindo: participação, realização das atividades, exercícios variados, provas, questionamentos, produção de textos, relatórios dos alunos, atividades lúdicas, trabalho em duplas e individuais, etc.

PALAVRAS-CHAVE: Avaliação. Prática docente. Ensino e aprendizagem. Ensino Fundamental.

\section{Introdução}

Atualmente o Brasil passa por transformações no que diz respeito à avaliação do desempenho escolar, visto que por muito tempo a principal preocupação era a atribuição de notas, que resultavam na promoção ou reprovação do aluno. Mais recentemente outras formas de compreender o processo de avaliação foram surgindo e, sendo assim, é importante entender como os professores que atuam diretamente com crianças do Ensino Fundamental pensam e agem em relação à avaliação do desempenho escolar.

\footnotetext{
${ }^{1}$ Doutora em Educação. PUCRS - Pontifícia Universidade Católica do Rio Grande do Sul. Professora Adjunta. UFMS - Universidade Federal de Mato Grosso do Sul. Líder do Grupo de Estudo e Pesquisa em Desenvolvimento, Gênero e Educação. Naviraí - MS - Brasil. 79950-000 - josianeperes7@ hotmail.com. ${ }^{2}$ Graduada em Pedagogia. UFMS - Universidade Federal de Mato Grosso do Sul. Professora da Rede Municipal de Ensino. Naviraí - MS - Brasil. 79950-000 -. tamiresferreiraazevedo@ hotmail.com.
} 
Diante dessa questão, justifica-se a presente pesquisa que tem por objetivo investigar a opinião e prática de professoras que atuam nos anos iniciais do Ensino Fundamental em escolas públicas de Naviraí - MS, no que diz respeito à avaliação do desempenho escolar dos alunos. Considerando que ao se referir à avaliação ainda subentende-se a questão da nota necessária para aprovação ou não, surge à problemática que norteia este trabalho que é: O que é, segundo a opinião das professoras, a avaliação, qual sua importância nos anos iniciais do Ensino Fundamental e quais práticas utiliza para avaliar os seus alunos?

Tais questionamentos se fazem necessários porque o desempenho escolar da criança nos anos iniciais envolve muitas exigências e por isso tornou-se foco de estudos de alguns profisssionais da área da educação preocupados com o processo de ensino e aprendizagem. Compreendido como uma maneira de analisar aspectos qualitativos da capacidade da criança em acompanhar os conteúdos propostos pela escola, o desempenho escolar pode refletir concepções inadequadas de avaliação, isolando a aprendizagem do processo educativo.

Portanto, as concepções sobre avaliação de desempenho sempre tiveram interpretações diferentes, sendo então a avaliação utilizada como recurso, de acordo com o objetivo julgado necessário naquele momento, o que nos leva a discussão do que considerar na avaliação de desempenho nos anos iniciais no contexto atual.

Muitas são as dificuldades que os professores apresentam em como avaliar nos seus alunos, a proposta é investigar as metodologias que os mesmos utilizam e refletir sobre sua prática. É importante destacar que hoje muitos docentes buscam avaliar o aluno através de seus próprios conhecimentos. Desta forma, o professor poderá perceber até onde a metodologia usada está tendo sucesso e a onde precisa mudar para atender a todos os educandos. As metodologias utilizadas podem contribuir para o aprendizado de alguns e de outros não. O professor necessita trabalhar várias metodologias para que assim todos os alunos possam chegar a ótimos resultados.

No caso do presente estudo, trata-se de uma pesquisa qualitativa, com coleta de dados empíricos realizados junto a docentes do $2^{\circ}$ ano do ensino fundamental, cujo resultado aqui apresentado encontra-se assim sistematizado: na primeira parte será apresentada a fundamentação teórica com abordagem de alguns autores que discutem a temática; na segunda etapa será feita a explicação de como se deu o encaminhamento metodológico para a realização da coleta de dados; na terceira etapa são apresentados os 
resultados da pesquisa, juntamente com as discussões, sempre estabelecendo relações com o referencial teórico.

O resultado esperado com esta pesquisa é poder contribuir com a melhor compreensão dos docentes sobre o real sentido da avaliação. Antes, porém se faz necessário fundamentar em estudos a respeito do tema, para melhor compreender a realidade encontrada em Naviraí. Assim, o referencial teórico a seguir aborda assuntos relativos à avaliação nos anos iniciais do Ensino Fundamental.

\section{Fundamentação teórica}

A palavra avaliar vem do latim $a+$ valere que significa atribuir valor e mérito ao objeto em estudo, conforme Santos et al. (2010). Portanto, de acordo com o significado original da palavra, avaliar é atribuir um juízo de valor e, nesse sentido, Luckesi (1996, p.33) destaca que a avaliação "[...] é como um julgamento de valor sobre manifestações relevantes da realidade, tendo em vista uma tomada de decisão".

Para Franco (1998, p.119), “Avaliar é uma atividade tão antiga quanto o surgimento da consciência humana". Segundo a autora, desde que os homens começaram a se comunicar, iniciaram o processo de se avaliar, se analisar e se julgar.

De acordo com Sobrinho (2002, p.167),

[...] uma avaliação, além de tomar decisões, deve também conduzir a transformações. Se ela não transformar, qualitativamente, e se não oferecer elementos de reflexão para ações de transformação e melhoria, não cumpre o seu papel do ponto de vista educacional.

O ato de avaliar é amplo e não se restringe a um único objetivo, é uma ação que requer responsabilidade, conhecimento, experiência e exige uma tomada de decisão. Os conceitos sobre avaliação são muitos e as formas de avaliar variam de acordo com o objetivo a ser alcançado.

De acordo com Demo (1999, p.1):

Refletir é também avaliar e avaliar é também planejar, estabelecer objetivos etc. Daí os critérios de avaliação, que condicionam seus resultados estejam sempre subordinados a finalidades e objetivos previamente estabelecidos para qualquer prática, seja ela educativa, social, política ou outra. 
Entende-se, portanto, que a avaliação não consiste em só avaliar o aluno, mas o contexto escolar na sua totalidade, permitindo fazer um diagnóstico para sanar as dificuldades do processo de aprendizagem, no sentido teórico e prático.

A avaliação, na concepção de Both (2007), vem atrelada ao processo, onde se direciona a qualidade do desempenho sobre a quantidade de atividades propostas, tanto para o aluno quanto para o professor, ficando em um processo comparativo. Porém na visão do autor, o foco principal é a qualidade do ensino, ultrapassando os limites da verificação.

Segundo Libâneo (1994), a avaliação é como uma tarefa necessária e permanente do trabalho docente e deve acompanhar passo a passo o processo de ensino e aprendizagem. O autor ressalta ainda que através da avaliação que se obtêm os resultados para serem comparados aos objetivos propostos. Assim, constatam-se os progressos, as dificuldades e são permitidas as correções necessárias.

Através dos resultados alcançados por meio das avaliações é que os docentes percebem se atingiram seus objetivos. Vale ainda ressaltar que avaliar é buscar progredir a cada resultado negativo e assim consertar os erros cometidos durante o caminho. Tornando os erros em aprendizagens, as dificuldades em experiências.

Libâneo (1994, p.195) afirma que:

\begin{abstract}
A avaliação é uma reflexão sobre o nível de qualidade do trabalho escolar tanto do professor como dos alunos. Os dados coletados no decurso do processo de ensino, quantitativos ou qualitativos, são interpretados em relação a um padrão de desempenho e expressos em juízos de valor (muito bom, bom, satisfatório, etc.) acerca do aproveitamento escolar. A avaliação é uma tarefa complexa que não se resume a realização de provas e atribuição de notas. A mensuração apenas proporciona dados que devem ser submetidos a uma apreciação qualitativa. A avaliação, assim, cumpre funções pedagógico-didáticas, de diagnóstico e de controle em relação as quais se recorrem a instrumentos de verificação do rendimento escolar.
\end{abstract}

Os Parâmetros Curriculares Nacionais (PCNs) trazem uma orientação para avaliação nos anos iniciais que ultrapassa a visão da avaliação tradicional, "[...] para ser entendida como parte integrante e intrínseca ao processo educacional" (BRASIL, 1997, p.55). O documento apresenta a avaliação como subsídio ao professor, para uma reflexão contínua sobre sua prática, na perspectiva de criar novos instrumentos de trabalho e retomar aspectos a serem revistos e adequá-los ao processo de aprendizagem.

Em relação ao aluno, o documento apresenta as seguintes considerações: 
[...] é instrumento de tomada de consciência para suas conquistas, dificuldades e possibilidades para a reorganização de seu investimento na tarefa de aprender. Para a escola, possibilita localizar quais aspectos das ações educacionais demandam maior apoio. (BRASIL, 1997, p.55).

A avaliação é como um diálogo, onde docentes buscam encontrar formas de ensinar e a de procurar os percursos que contribui para a aprendizagem dos alunos. Nos dias atuais muitos dos docentes buscam avaliar apenas por nota, não levando em consideração o saber do aluno. Os docentes não devem apenas ensinar, mas fazer com que os alunos aprendam.

A sala de aula é um lugar que deve produzir conhecimentos, gerar valores e competências daqueles que ensinam e daqueles que aprendem. Ou seja, é importante que os docentes a cada dia busquem novas práticas pedagógicas, que contribuam para o ensino e aprendizagem dos alunos. É necessário que os professores (as) ofereçam a seus educandos a oportunidade de desenvolver suas capacidades.

Quanto aos tipos de avaliação, Kraemer (2006) destaca que existem três tipos com características próprias, que são avaliação somativa, formativa e diagnóstica, sendo que cada uma delas será analisada na sequência.

Para o referido autor, a avaliação mais comum é a somativa, que detecta o nível de rendimento realizando um balanço geral, no final de um período de aprendizagem, podendo classificar de acordo com o nível de aprendizagem. Haydt (1988, p.25) afirma que “A avaliação somativa supõe uma comparação, pois o aluno é classificado segundo o nível de aproveitamento e rendimento alcançado, geralmente em comparação com os demais colegas, isto é, com o grupo classe.” E acrescenta que em um sistema escolar seriado, faz-se necessário “[...] promover os alunos de uma série para outra, e de um grau ou curso para outro. O aluno vai ser promovido de acordo com o aproveitamento e o nível de adiantamento alcançado".

A avaliação formativa destaca-se por ser um processo contínuo, onde o ponto de partida é o critério de transformar a avaliação em um instrumento que evolui e pode ser melhorado com o tempo, a saber, aprender a aprender. É importante que o professor passe segurança ao aluno, para que o mesmo se sinta seguro para expressar suas dúvidas e dificuldades. Podendo assim aprender e adquirir o conhecimento.

Gil (2006, p.247) a define da seguinte forma: 
A avaliação formativa tem a finalidade de proporcionar informações acerca do desenvolvimento do processo de ensino e aprendizagem, para que o professor possa ajustá-lo às características dos estudantes a que se dirige. Suas funções são as de orientar, apoiar, reforçar e corrigir.

É importante que os docentes além de professores, sejam orientadores de seus alunos rumo à aprendizagem. Contribuindo para que o aluno possa ver e rever suas dificuldades e compreender seus erros e não cometê-los mais. Dessa forma, provavelmente tanto professores quanto alunos descobrirão em que estão errando e poderão progredir a cada dia. Hadji (2001, p.9) fala sobre o conceito de avaliação formativa, que se constitui em:

[...] uma avaliação que se consagre à regulação das aprendizagens, capaz de orientar o aluno para que ele próprio possa situar suas dificuldades, analisá-las e descobrir, ou pelo menos, operacionalizar os procedimentos que lhes permitam progredir. Nessa perspectiva, o erro não seria uma falta a ser reprimida, mas uma fonte de informação, e isso tanto para o professor - cujo dever é analisar a produção e, através dela, a situação do aluno - como para o aluno, que precisa compreender seu erro para não mais cometê-lo e progredir.

A outra modalidade de avaliação é a diagnóstica, cuja ênfase é identificar os conteúdos e competências, objetivando saber qual nível encontra-se o aluno, bem como destacar que o seu principal foco não é voltado à nota, mais em um diagnóstico para compreender o processo da produção do conhecimento.

Ao referir-se sobre a avaliação diagnóstica, Gil (2006, p.247) revela que:

Constitui-se num levantamento das capacidades dos estudantes em relação aos conteúdos a serem abordados, com essa avaliação, buscase identificar as aptidões iniciais, necessidades e interesses dos estudantes com vistas a determinar os conteúdos e as estratégias de ensino mais adequadas.

Entretanto, a realidade tem apresentado padrões de avaliações bem diferentes das que foram acima citadas, considerando ainda as metodologias utilizadas para avaliar. Assim, fica evidente que pouca coisa tem mudado dentro das instituições escolares, tendo em vista que o desempenho escolar ainda demonstra índices alarmantes de pouca qualidade. $\mathrm{O}$ problema do desempenho nos remete à questão da seletividade social dentro da escola. O Brasil é um país de pouca cultura, investe-se pouco em educação e faltam também ações governamentais que expressem claramente a 
determinação de enfrentar o desafio de fazer da educação um instrumento para a construção de um mundo mais justo e menos desigual.

Há uma forte tendência, principalmente dos professores, em responsabilizar a criança pelo desempenho, impondo-lhe uma responsabilidade que deveria ser compartilhada, pois talvez o problema não esteja apenas na aprendizagem, mas também na maneira de ensinar. Portanto, há que se considerar que muitos outros fatores interferem no bom desempenho escolar e principalmente na permanência dos alunos na escola. Entre os quais podemos destacar a participação da família, o contexto social, as políticas públicas educacionais, a formação docente, as metodologias de ensino e a atuação do gestor diante dos desafios enfrentados pela escola.

Quanto à participação da família, é fundamental para o processo de ensino e aprendizagem da criança, conforme evidencia a LDB, no Art. $2^{\circ}$ :

\begin{abstract}
A educação, dever da família e do Estado, inspirada nos princípios de liberdade e nos ideais de solidariedade humana, tem por finalidade o pleno desenvolvimento do educando, seu preparo para o exercício da cidadania e sua qualificação para o trabalho. (BRASIL, 1996, não paginado).
\end{abstract}

A importância da participação dos pais na vida escolar dos filhos tem apresentado um papel importante no desempenho escolar. $\mathrm{O}$ diálogo entre a família e a escola, tende a colaborar para um equilíbrio no desempenho escolar, o que é possível considerar que a criança e os pais trazem consigo uma ligação íntima com o desempenho. De acordo com Carvalho (2004, p.144):

O sucesso escolar tem dependido, em grande parte do apoio sistemático da família que investe nos filhos, compensando tanto as dificuldades individuais quanto as deficiências escolares. Trata-se, em geral de família dotada de recursos econômicos e culturais, dentre os quais se destacam o tempo livre e o nível de escolarização dos pais.

Entretanto, a escola não deve impor à família as tarefas que lhe cabem. O papel da escola também está expresso na LDB (Art. $3^{\circ}$, Par. I - XI):

O ensino será ministrado com base nos seguintes princípios: igualdade de condições para o acesso e permanência na escola; liberdade de aprender, ensinar, pesquisar e divulgar a cultura, o pensamento, a arte e o saber; pluralismo de ideias e de concepções pedagógicas; respeito à liberdade e apreço à tolerância; coexistência de instituições públicas e privadas de ensino; gratuidade do ensino público em 
estabelecimentos oficiais; valorização do profissional da educação escolar; gestão democrática do ensino público, na forma desta lei e da legislação dos sistemas de ensino; garantia de padrão de qualidade; valorização da experiência extraescolar; vinculação entre a educação escolar, o trabalho e as práticas sociais. (BRASIL, 1996).

Vianna (2003, p.43) ressalta que a avaliação educacional, a partir dos anos 90, passou a ser usada, no contexto brasileiro, em diversos níveis administrativos, “[...] como tentativa de encontrar um caminho para a solução de alguns problemas educacionais. Assim, esperavam que os processos avaliativos determinassem a elevação dos padrões de desempenho da educação". Porém, como afirma esse autor, “[...] as avaliações apontam problemas, mas não os solucionam; outros caminhos deverão ser perseguidos".

Quanto ao processo de ensino e aprendizagem, ele se realiza por meio da interação professor e aluno, mas por si essa interação não resolve inteiramente a questão. A esse respeito Vianna (2003, p.47) aponta que:

Fatores externos à escola, inteiramente conhecidos pelos que transitam no mundo da pesquisa educacional, também têm importante papel no sucesso escolar, sendo suficiente citar alguns poucos como, entre outros, a equivalência idadelsérie; horas de estudo no lar e a participação efetiva da família no acompanhamento das atividades escolares. O fracasso ou o baixo desempenho numa avaliação, portanto, nem sempre, está relacionado ao professor, que muitas vezes, por si, não tem condições de atuar, visando à eliminação desses fatores.

Para o autor, a função de regulação é uma das mais importantes características dessa avaliação, pois a mesma permite que o professor, assim como o aluno, corrija sua ação e a modifique se necessário, para obter melhores resultados.

Perrenoud (1999, p.168) alerta que “[...] enquanto a escola der tanto peso à aquisição de conhecimentos descontextualizados e tão pouco à transferência e à construção de competências, toda avaliação correrá o risco de se transformar em um concurso de excelência".

No caso da fase inicial do Ensino Fundamental, a baixa frequência é alarmante e parece haver uma falta de preocupação por parte dos pais em relação à frequência dos alunos, que chegam a não comparecer por meses em sala de aula. Assim, o trabalho do professor alfabetizador fica prejudicado, pois o aluno perde a sequência do conteúdo, ficando alheio nos dias em que comparece, ao conhecimento sistematizado trabalhado 
em sala e acaba muitas vezes desmotivado e sem interesse em dar continuidade aos estudos.

Além do mais, ao frequentar uma turma de $2^{\circ}$ ano, em que a exigência é maior e o processo de avaliação é classificatório, torna-se mais difícil para o aluno acompanhar se já não teve uma formação adequada no ano anterior. No caso da avaliação, é muito comum que neste período as crianças passem a ter medo devido à pressão feita pela escola e pelos pais e porque os resultados das avaliações, especialmente da nota das provas, evidenciam o sucesso ou insucesso dos alunos.

De acordo com os estudos realizados por Gonçalves et al. (2010), em que buscava identificar quando começava o medo de avaliação nos estudantes, os resultados evidenciaram que era justamente nas turmas de $2^{\circ}$ ano do ensino fundamental. Na fase anterior as crianças até gostavam de fazer as "provinhas" que não tinham caráter classificatório, mas no ano seguinte já começava o medo de fazer as avaliações, devido a preocupação com os resultados retratados pela aprovação ou reprovação.

Portanto, a avaliação é um procedimento necessário para acompanhar o desempenho do aluno e o trabalho desenvolvido pelo professor, sendo possível redirecionar as metodologias de ensino conforme a necessidade da turma. No caso do $2^{\circ}$ ano do Ensino Fundamental, o processo avaliativo não costuma ser tão simples para a criança, porque resulta em aprovação ou reprovação, algo que não ocorria na fase anterior e que os alunos não estavam acostumados.

Sendo assim, é importante haver o aprofundamento dos estudos sobre essa temática, como é o caso desta pesquisa, para que compreendendo melhor a problemática inerente a avaliação, os profissionais da educação possam cada vez mais utilizar-se do processo avaliativo como um mecanismo necessário ao processo de ensino e aprendizagem.

\section{Procedimentos metodológicos}

Para melhor entender como foi desenvolvida a presente pesquisa, faz-se necessário explicar como se deu o encaminhamento metodológico. Para Minayo (2003) a metodologia de pesquisa é o caminho do pensamento a ser seguido. Ocupa um lugar central na teoria e trata-se basicamente do conjunto de técnicas a ser adotada para construir uma realidade, a pesquisa é assim, uma atividade básica da ciência na sua construção da realidade. 
O desenvolvimento deste estudo foi realizado por meio de uma abordagem qualitativa envolvendo um conjunto de metodologias e técnicas. Os sujeitos que fizeram parte desta pesquisa foram docentes que atuavam no $2^{\circ}$ ano do Ensino Fundamental em escolas municipais e estaduais de Naviraí - MS. O instrumento utilizado para a coleta de dados foi um questionário contendo 15 questões abertas, relacionadas ao tema "avaliação", sendo construído especialmente para este estudo, a partir dos conteúdos obtidos durante o processo de revisão da literatura.

De acordo com Parasuraman (apud MOISÉS; MOORI, 2007), um questionário é um conjunto de questões elaboradas para gerar os dados necessários para se atingir os objetivos de um projeto de pesquisa. É considerado um dos pontos principais para a realização da pesquisa, pois através dos dados contidos no questionário conseguimos atingir os objetivos propostos. Assim, a coleta de dados foi realizada através da utilização de questionário com questões abertas, que possibilitou a obtenção de respostas que evidenciassem a opinião dos professores. É importante destacar que foram entregues inicialmente 15 (quinze) questionários, cujo critério para a escolha dos participantes era atuar como docente em turmas do $2^{\circ}$ ano do Ensino Fundamental em escolas públicas de Naviraí. Entre esse total, somente 7 (sete) professoras devolveram o questionário preenchido, tornando-se portanto a totalidade dos dados que passaram a fazer parte deste estudo.

Vale ressaltar que desde o início a intenção era desenvolver a pesquisa junto a professores que atuavam nos anos iniciais do Ensino Fundamental, mas ao se constatar que cada um dos anos ou séries possui características próprias, como no caso do $1^{\circ}$ ano em que o aluno não fica retido, tornou-se necessário fazer a opção por apenas uma das séries. Assim, foi escolhido o $2^{\circ}$ ano do Ensino Fundamental, porque é nesta fase que as avaliações começam a ter a finalidade de aprovar ou reprovar os alunos, surgindo, portanto a necessidade de investigar o que os professores pensam e como eles agem em relação à avaliação do desempenho escolar de seus alunos.

Quanto ao procedimento para a realização da coleta de dados, foi feito contato primeiramente com os diretores das escolas e depois com os professores que atuavam em turmas de $2^{\circ}$ ano. Foram entregues os questionários e estipulado um prazo de até 15 (quinze) dias para devolver preenchido. Porém, conforme citado anteriormente, ao retornar nas escolas nem todos os docentes haviam respondido e por já não haver mais tempo, os 7 (sete) professores que se dispuseram a contribuir, tornaram-se a amostra do presente estudo, cujos resultados serão apresentados e analisados na sequência. 


\section{Resultados e discussão}

Para organização e discussão dos resultados, será mantida a seguinte organização: primeiramente será apresentado o perfil das professoras que fizeram parte da pesquisa; em seguida serão apresentados os dados obtidos através dos questionários, sendo selecionadas as questões que continham informações relevantes, compatíveis com o objetivo deste estudo, e em cada uma das questões analisadas são apresentadas as respostas das professoras. A discussão dos resultados ocorre de forma intercalada com as respostas das professoras, sendo relacionado com autores que abordam a temática.

\section{Perfil das professoras que representam a amostragem da pesquisa}

Para melhor visualizar o perfil das 7 (sete) professoras que representam a amostra da presente pesquisa, as informações obtidas através do questionário foram sistematizadas e apresentadas através do Quadro 1, em que aparecem as principais informações sobre as participantes, bem como seus nomes fictícios, que foram utilizados para preservar a identidade das professoras.

Quadro 1 - Perfil das professoras pesquisadas

\begin{tabular}{|c|c|c|c|c|c|c|}
\hline Prof. & Id & $\begin{array}{l}\text { Tempo } \\
\text { prof. } \\
\text { (anos) }\end{array}$ & $\begin{array}{c}\text { E no } \\
2^{\circ} \text { ano }\end{array}$ & Formação Profissional & $\begin{array}{c}\text { Carga } \\
\text { horária }\end{array}$ & $\begin{array}{l}\text { Regime de } \\
\text { trabalho }\end{array}$ \\
\hline Antônia & 50 & 20 & 20 & $\begin{array}{l}\text { Magistério, Normal Superior, Pedagogia, } \\
\text { Especialização em Séries Iniciais e Educação } \\
\text { Infantil. }\end{array}$ & $20 \mathrm{~h}$ & Contratada \\
\hline Elizabete & 39 & 5 & 1 & $\begin{array}{l}\text { Magistério, Especialização em Educação Infantil } \\
\text { Pedagogia em andamento. }\end{array}$ & $20 \mathrm{~h}$ & Contratada \\
\hline Francisca & 38 & 2 & 1 & Normal Superior, Pedagogia em andamento. & $20 \mathrm{~h}$ & Contratada \\
\hline Lúcia & 26 & 6 & 3 & $\begin{array}{l}\text { Normal Superior, Pedagogia, Especialização em } \\
\text { Educação Infantil e Séries Iniciais, } \\
\text { Psicopedagogia e Educação Especial. }\end{array}$ & $40 \mathrm{~h}$ & Contratada \\
\hline Maria & 42 & 20 & 4 & $\begin{array}{l}\text { Ensino Superior com Especialização em Séries } \\
\text { Iniciais e Educação Especial }\end{array}$ & $20 \mathrm{~h}$ & Contratada \\
\hline Rosa & 54 & 23 & 10 & Magistério e Normal Superior & 20 & Concursada \\
\hline Zilda & 43 & 15 & 3 & $\begin{array}{l}\text { Normal Superior, Especialização em Educação } \\
\text { Infantil e Séries Iniciais e também Educação } \\
\text { Especial. }\end{array}$ & $40 \mathrm{~h}$ & $\begin{array}{l}\text { Concursada e } \\
\text { Contratada }\end{array}$ \\
\hline
\end{tabular}

Fonte: Elaboração própria.

Através das informações contidas no Quadro 1, é possível perceber que a idade das professoras varia entre 26 e 54 anos, cujo tempo de trabalho era de 2 a 23 anos. No caso da atuação em turmas do $2^{\circ}$ ano do Ensino Fundamental, os dados do questionário 
indicaram que uma delas trabalhou o tempo todo somente neste nível de ensino, 20 anos, uma tinha 10 anos de experiência e duas professoras estavam atuando pela primeira vez com turmas de $2^{\circ}$ ano.

Quanto à formação profissional, a maioria tem graduação e especialização na área, apenas duas ainda estava cursando pedagogia. Apesar de terem curso superior, a maioria das professoras era apenas contratada, somente uma era concursada e outra que tinha um período de concurso e outro de contrato.

\section{Opinião das professoras sobre avaliação escolar}

Entre as questões que faziam parte do questionário, que foi o instrumento utilizado para a realização desta pesquisa, uma indagava diretamente sobre o que é avaliação e porque é necessário avaliar os alunos. As respostas foram às seguintes:

- Lúcia: “Avaliação mostra o nível de aprendizado de cada aluno e também busca identificar possíveis problemas no método de ensino".

- Maria: "É observar, verificar, analisar e interpretar o conhecimento de aprendizagem entre professor e aluno, para diagnosticar como educadora se atingimos os parâmetros do conhecimento dos alunos do início ao fim de todo aprendizado que ele captou o percurso aprendido".

- Elizabete: “Avaliação é uma forma de observar a aprendizagem do aluno, seu desenvolvimento. Avaliando podemos verificar se os objetivos de ensino estão sendo alcançados".

- Zilda: "É o processo pelo qual você vai organizar todo o seu caminhar na sala de aula. É a partir dali que criamos nossas metodologias".

Podemos notar através das respostas das professoras, que o ato de avaliar é compreendido como forma de se autoavaliar, ao mesmo tempo em que se avalia o nível de desempenho do aluno. Trata-se de um fato interessante porque nem sempre os professores têm essa noção de que a avaliação aponta indicativos sobre o andamento do seu trabalho. Muitos acreditam que a avaliação se refere somente ao desempenho do aluno. Nesse sentido, Both (2007) postula que a avaliação direciona a qualidade do desempenho sobre a quantidade de atividades realizadas, tanto para os alunos quanto para os professores, tratando-se, portanto de um processo comparativo.

As professoras também comentam que o ato de avaliar é necessário para verificar se os objetivos foram atingidos, para poder criar novas metodologias, de acordo com o que foi percebido durante o processo avaliativo. Nesse sentido, Tyler 
(1975) enfatiza que o ato de avaliar é necessário para saber se os objetivos educacionais estão sendo alcançados, conforme o programa do currículo e do ensino e, consequentemente, se está havendo modificações desejáveis nos padrões de comportamento dos estudantes. Ou seja, a avaliação contribui para direcionar a prática docente, pois evidencia como está a situação dos alunos em relação aos conteúdos que foram ensinados em sala de aula.

Outra questão contida no instrumento de pesquisa se referia à maneira, ou como as professoras costumavam avaliar os alunos e, entre outras respostas, foi destacado pelas docentes: "Avalio através de sondagens, sala de aula, e participação dos alunos nas aulas ministradas" (Rosa). "Costumo Avaliar de maneira quantitativa, se a aprendizagem está ocorrendo conforme a grade curricular e também qualitativa, de que maneira o aluno está aprendendo, seu esforço..." (Elizabete). "Proponho a eles uma situação problema na qual ele irá vivenciar o momento e assim buscar uma forma de resolver dentro dos limites de seus conhecimentos e aprendizados" (Maria). "Através das notas obtidas nas avaliações, participações, e registros das atividades" (Lúcia) "Avalio no dia a dia e também de forma de provas bimestrais" (Antônia). "A avaliação é diária, através dos exercícios propostos em sala de aula e também através de provas bimestrais" (Zilda).

Tais respostas evidenciam que as professoras costumam avaliar de forma a perceber se os alunos atingiram os objetivos desejados e também elas utilizam os três tipos de avaliações para verificar o desempenho dos seus alunos, ou seja, a diagnóstica, a formativa e somativa (KRAEMER, 2006).

Em relação às atividades práticas utilizadas como instrumento usado para avaliar seus alunos, as participantes da pesquisa assim afirmam:

- Antônia: "Participação e realização das atividades, avaliações bimestrais".

- Elizabete: "Exercícios, provas, questionamentos, observação".

- Francisca: "Produção de textos, atividades construtivas com figuras".

- Lúcia: "Atividades lúdicas, trabalho em duplas, trabalhos e avaliação individual".

- Maria: “Aplicação de provas, testes, realização de tarefas, trabalhos, fichas individuais, claro que nós educadoras podemos ainda melhorar a nossa prática, e contribuir para a aprendizagem dos alunos através de pesquisas e outros métodos que ajude esses alunos". 
- Rosa: “Atividades mimeografadas, relatório dos alunos, questionários, objetivos, atividades com lacunas e opções múltiplas”.

- Zilda: "Provas, atividades no caderno e atividades em sala".

Esses dados indicam que cada professora tem suas metodologias para a avaliação de seus alunos. Procuram avaliar de acordo com as necessidades encontradas na turma. Desta forma pode se perceber que há muitas maneiras de avaliar e cabe a cada professor ver qual prática é a mais adequada e contribuirá para a aprendizagem de seus alunos.

Segundo Hoffmann (2005, p.121), os melhores instrumentos de avaliação “[...] são todas as tarefas e registros feitos pelo professor que o auxiliam a resgatar uma memória significativa do processo, permitindo uma análise abrangente do desenvolvimento do aluno". Assim, o processo de avaliação faz parte do dia a dia, sendo possível avaliar os alunos diariamente de diferentes maneiras, sem priorizar somente as provas, mas utilizar várias metodologias que provavelmente irão contribuir para o desenvolvimento dos alunos.

Quando questionadas sobre com que frequência avaliam os seus alunos, a maioria das professoras disse que avalia diariamente, bimestralmente e mensalmente. Já Elizabete afirmou que avalia ao término de cada conteúdo programado para verificação da aprendizagem e diariamente para observar o desenvolvimento dos alunos. Diante dos fatos aqui mencionados percebemos que mesmo sendo professores de escolas diferentes e de possuírem pensamentos diferentes, as professoras costumam avaliar aos alunos de forma semelhante.

Em relação ao que costumam fazer após o resultado das avaliações, as professores tiveram respostas diversificadas, tais como: A Elizabete disse: "Presto contas através de notas, pois avaliação classificatória e quantitativa é necessária. Para aqueles resultados abaixo da média existem vários recursos entre eles aulas de reforço". Já Lúcia e Rosa declararam que se a maioria tiver um resultado abaixo do esperado, retomam o conteúdo e fazem outra avaliação. Lúcia ainda complementou: "No caso dos alunos com dificuldades, valorizo o que eles sabem, mas as notas são de acordo com o nível de cada aluno". Maria relatou "Analiso cada avaliação com muita atenção, observando cuidadosamente se obtive o resultado que pretendia atingir". Antônia mencionou que "Observo se os conteúdos foram aplicados de forma correta. Porque se em um determinado conteúdo a sala foi de forma parcial negativo os mesmos serão 
revisados em forma de avaliações paralelas". Zilda assim afirmou: "Procuro reavaliar a metodologia e preparar novos métodos".

Com essas práticas pedagógicas predominam os três tipos de avaliação, conforme Kraemer (2006), ou seja, diagnóstica, formativa e somativa, na qual cada uma contribui de alguma forma para o desenvolvimento e aprendizado do aluno, tendo como foco principal o ensino de qualidade.

Questionadas sobre como percebem que atingiu os resultados, as professoras disseram que é através dos resultados positivos, participação e pelo nível de aprendizagem e de entendimento do aluno. Quando o docente se dedica totalmente ao aprendizado das crianças, os mesmos percebem que é por meio da dedicação em ensinar que se constrói o caminho do sucesso tanto dele como dos alunos.

Considerando que atualmente no $1^{\circ}$ ano do Ensino Fundamental não acontece a avaliação somativa, entendida como aquela que tem a finalidade de promover os alunos de uma série para outra e de um grau ou curso para outro (HAYDT, 1988), as docentes também responderam a seguinte questão: Pra você, o fato de o aluno não ser reprovado, isso prejudica a avaliação quando ele vai para o $2^{\circ}$ ano? Essa questão resultou em respostas divergentes por parte das professoras pesquisadas, sendo que 4 tinham a opinião de que prejudica, e 3 tiveram outro ponto de vista. Assim elas responderam:

- Francisca: “Acredito que de certa forma o aluno é prejudicado, pois ele ainda está imaturo ao desenvolvimento e as cobranças vão aumentar no decorrer do ano letivo".

- Maria: "No meu ponto de vista é prejudicial, porque ele entra no $2^{\circ}$ ano sem ler e escrever, é raro quando o educador consegue alguns alunos lendo, mas cabe ao professor do $2^{\circ}$ ano alfabetizar".

- Lúcia: “Com certeza prejudica, pois se cobra pouco no $1^{\circ}$ ano ou o aluno não aprendeu o suficiente e quando vai para o $2^{\circ}$ ano não tem todas competências necessárias, dificultando o trabalho do professor e o processo de avaliação do aluno, principalmente quando ele possui dificuldades".

- Antônia: "Prejudica, pois o aprendizado de cada aluno na alfabetização acontece de forma diferente, cada qual apresenta seu resumo".

As três professoras que tiveram opiniões diferentes assim justificaram:

- Zilda: "Acredito que contribui no processo educacional porque a aprendizagem é contínua e a auto-estima também é elevada”. 
- Rosa: "Depende da professora do $1^{\circ}$ ano, porque se a professora for responsável ela fará tudo que estiver ao seu alcance para garantir o aprendizado de seus alunos".

- Elizabete: Acho que não prejudica, porque a alfabetização no $1^{\circ}$ ano não é obrigatória. Ela pode ocorrer ou não. Com 6 anos de idade algumas crianças estão preparadas para ler e escrever, mas outras nunca frequentam uma escola e mal sabem pegar em um lápis. Não seria justo reprovar estes alunos.

Diante das respostas mencionadas acima podemos notar divergências nas opiniões. Algumas professoras acreditam que o fato do aluno não ser reprovado no $1^{\circ}$ ano, prejudica quando ele vai para o $2^{\circ}$ ano, pois muitos vão imaturos sem ao menos saber escrever e isso interfere no desenvolvimento dos alunos mais avançados. Algumas disseram que não, pois isso varia de professor para professor vai depender das metodologias utilizadas por cada um. Trata-se de um assunto polêmico que envolve todos os profissionais de educação, sendo assim, é importante que haja novas pesquisas na área para melhor compreender essa problemática.

As professoras também foram indagadas, através do questionário, sobre a importância que a avaliação tem na vida do aluno. Rosa assim respondeu: "Nenhuma, porque a avaliação é feita para atender aos interesses do professor, do município, do Estado e do Brasill". Antonia afirmou: "Aprende que desde cedo ele será avaliado em tudo que fizer na vida". Lúcia enfatizou: “A avaliação possui uma importância fundamental na vida do aluno, para medirmos o nível que cada aluno se encontra, para mostrarmos aos pais. Para que o próprio aluno se autoavalie. Assim podendo buscar melhorias no seu desempenho escolar". Maria afirmou "Serve para aprimorar seus conhecimentos e aprendizagem, adquiridos para formar um bom cidadão, capacitado". Disse Francisca: "É uma forma de observar melhor seu conhecimento". Zilda relatou: "É o mecanismo pelo qual o aluno é direcionado o foco da sua aprendizagem, é onde o professor traça suas metas, métodos, estratégias e atividades a serem trabalhadas".

Tais respostas evidenciam que, segundo a opinião da maioria das professoras, a avaliação é muito importante para o aluno, para ele possa ver e rever suas atitudes, perceber que na vida tudo é avaliado desde conhecimentos a questão de valores. É importante enfatizar que quando adultos também serão avaliados não como alunos, mas como profissionais. Apenas Rosa acredita que a avaliação não tem nenhuma importância na vida dos alunos, segundo ela a avaliação é para analisar o resultado dos professores, seus erros, dificuldades e acertos. Para Vianna (2003), a avaliação permite 
que o professor, assim como o aluno, corrija sua ação e a modifique se necessário, para obter melhores resultados. Ou seja, ela é importante tanto para os alunos quanto para os professores.

Questionadas sobre alguma experiência que contribuiu para o aprendizado dos alunos e para sua avaliação pessoal, Elizabete disse: "Trabalho em grupo de alunos com pesquisa sobre o tema, apresentação para a turma. Houve aqueles que aprenderam sobre o conteúdo, aqueles não participaram por falta de interesse e ainda outros com dificuldades de se expressar. A maioria assimilou o conteúdo de forma positiva. Rosa disse que: "Para alunos não tenho uma experiência específica, mas para mim a avaliação é como um espelho que reflete o meu desempenho". Zilda disse: “Observação na realização de atividades na sala de aula, é nesse momento que você percebe realmente o que o aluno sabe". Maria argumentou: "Procuro estimular a leitura através da 'mala viajante', que é toda enfeitada com lápis de cor, borracha, lápis de escrever e um livro ata para eles poderem desenhar o que acharam da história, que ele ou os pais vão contar, é um incentivo para os pais contar historinhas com os filhos, dentro da mala vai todo esse material e 3 livrinhos de história. Formo grupo de 2 ou 4 crianças e coloco o alfabeto móvel para eles manusearem e formar novas palavras".

As respostas indicam que são muitas as experiências que podem ser vividas, em relação a avaliação. O profissional da educação é o responsável pelos profissionais do amanhã. E para que alcance os objetivos desejados é importante que os professores ao avaliar seus alunos, encontrem caminhos que possam contribuir para gerar grandes experiências, novas formas avaliativas que não fique apenas em provas, mas em atividades diferenciadas que despertem o interesse dos alunos.

Questionadas sobre qual mensagem deixaria para os futuros professores sobre o ato de avaliar, Lúcia declarou: "Para se tornar um profissional é preciso trabalhar com amor, estar preparado para os desafios que vão aparecer e pegar como aprendizado, pois nós seres humanos nunca sabemos tudo, temos que estar abertos a aprender todos os dias de nossa vida". Francisca disse que: "Os futuros professores não se desanime com as primeiras experiências negativas, pois será dessa maneira que irá melhorar seu conhecimento". Antônia ressaltou: “Avaliar é necessário e avaliar não é o ato de verificar os erros e acertos e sim de rever novas metodologias para chegar ao aluno o aprendizado". Zilda sugeriu: “Avaliem sempre com respeito ao ritmo de aprendizagem de cada aluno, é um ato importantíssimo no processo ensino e aprendizagem, mas não pode haver falhas". Elizabete destacou: "Existem muitas formas de avaliar um aluno, 
podemos usar apenas a avaliação classificatória quantitativa. Se o resultado não for satisfatório, deve-se saber lidar com ele”. Maria enfatizou: "Grande professor será aquele que realiza o que ensina, por isso faça com que as crianças descubram ou cria situações-problemas para descobrir a fase do saber fazendo, assim um olhar para o futuro. Porque não basta apenas ser professor, é preciso ser mestre na arte de ensinar. Com isso eu digo que você educador nunca desista por medo de fracassar, pois o fracasso não é o fim de tudo e sim uma parte do caminho para alcançar o sucesso".

As professoras também foram incentivadas a escrever livremente sobre alguma temática relacionada ao assunto que elas gostariam de comentar. A professora Antônia respondeu: "Avaliar alguém é muito difícil e requer muita seriedade e ética". Rosa disse: "Não, porque tem que $1^{\circ}$ conhecer o seu aluno para depois decidir a metodologia". Zilda afirmou "Não se prender simplesmente a prova, utilizar outros mecanismos". Elizabete argumentou: "O profissional da educação deve ter o cuidado na hora de analisar um aluno. Muitos reprovam uma criança por ela ter um mau comportamento. Outros beneficiam aqueles com os quais mais se identificam. A avaliação requer cuidados, consciência e imparcialidade". Maria comentou: "A estratégia visa essencialmente não só oferecer ao aluno uma atividade desafiadora, capaz de melhor envolvê-lo no trabalho escolar, como também acompanhar a ação pedagógica das diversas escolas conveniadas, uma vez que há um projeto comum sendo implementado".

De acordo com as respostas, podemos notar que avaliar requer novas práticas de ensino que venham contribuir para o desenvolvimento dos alunos. Avaliar é ter respeito e compromisso com os alunos. Fica claro que avaliar não é se prender apenas em provas, mas criar novos instrumentos avaliativos.

Diante das respostas acima mencionadas pelas professoras do $2^{\circ}$ ano, fica claro que é importante por em prática todos os tipos de avaliações, conforme Kraemer (2006). Dentre elas a diagnóstica, pois é através dela que fazemos uma avaliação conhecimento do aluno. A formativa que tem por objetivo levar o conhecimento ao aluno e ao mesmo tempo prévio sobre o valorizar o que ele já sabe. E a somativa que tem como principal característica a aprovação do aluno ou não. Todas elas são importantes e devem ser colocadas em práticas durante todo o processo educacional. 


\section{Considerações finais}

Partindo do princípio que a finalidade deste estudo era investigar a opinião e as práticas das professoras a respeito do processo de avaliação do desempenho dos alunos, após a realização da pesquisa foi possível constatar que, segundo a opinião das professoras, provas e exames não devem ser unicamente empregados como forma de avaliação. Embora muitos professores avaliem prioritariamente desta maneira, as professoras que fizeram parte desse estudo procuravam diversificar e valorizar as práticas e comportamentos dos alunos, apesar de também aplicarem provas, porque no $2^{\circ}$ ano do Ensino Fundamental a avaliação é também somativa, ou classificatória.

Assim, as professoras relatam que utilizam diversas maneiras para avaliar o desempenho dos alunos como: participação, realização das atividades, exercícios variados, provas, questionamentos, produção de textos, relatório dos alunos, atividades lúdicas, trabalho em duplas e individuais, etc. As professoras também tinham a opinião de que ao mesmo tempo em que avaliava a turma, elas também se autoavaliavam. Através do processo avaliativo, elas percebiam onde estavam às limitações para então tentar mudar suas práticas e metodologias visando a aprendizagem dos alunos. Avaliar é estar preocupado com o ensino e o ato de avaliar deve ser amplo e não se restringir a um único objetivo. Requer responsabilidade, conhecimento, experiência e exige uma tomada de decisão. Cada docente precisa avaliar de acordo com seus objetivos e realidade dos alunos.

Diante dos dados coletados foi possível perceber que a avaliação é um instrumento que contribui para a formação pessoal e profissional do professor e do aluno. Através da avaliação é possível medir conhecimentos, perceber erros e acertos. Trata-se de um processo para os docentes organizar o seu caminhar rumo a uma educação de qualidade.

No caso da avaliação na fase inicial do Ensino Fundamental, as professoras divergiram em relação à avaliação do $1^{\circ}$ ano, em que ocorre apenas a diagnóstica e formativa, sem existir a somatória, ou seja, nesta fase a criança não reprova, visto que é sempre promovida para o ano seguinte. Dessa forma, algumas professoras afirmaram que o fato de não existir a avaliação somatória, dificulta o trabalho no $2^{\circ}$ ano, porque os alunos chegam imaturos e sem algumas competências necessárias para continuar o seu processo de aprendizagem. Outras professoras, no entanto, disseram que depende muito de cada situação específica, porque ao iniciar o Ensino Fundamental com 6 anos de 
idade, a criança encontra-se despreparada para a avaliação classificatória, que ocorre especialmente através de notas.

Diante dessas divergências, e como a presente pesquisa não teve a pretensão de esgotar a temática, fica a sugestão para que novas pesquisas surjam na área, a fim de melhor compreender a complexidade relacionada ao processo avaliativo nos anos iniciais do Ensino Fundamental, especialmente nos $1^{\circ}$ e $2^{\circ}$ anos, em que a avaliação tem características diferenciadas de outros níveis de ensino.

E para finalizar, é importante destacar que a avaliação é um processo contínuo, que deve ocorrer nos mais diferentes momentos do trabalho escolar, e que tem a finalidade de verificar o desempenho dos alunos para então poder adequar as práticas de ensino de acordo com a realidade de sala de aula.

\title{
EVALUATION OF SCHOOL PERFORMANCE: VISION OF TEACHERS IN THE SECOND YEAR OF ELEMENTARY EDUCATION
}

\begin{abstract}
The present study aims to investigate the beliefs and practices of teachers in relation to the school performance of students, whose sample was composed by seven teachers who worked in the 2nd year of Elementary School in both state and municipal schools of Navirai - MS. The theoretical approach was guided by authors like Libâneo, Kraemer, Haydt, among others, that have relevant discussions on the subject, including three types of evaluations: diagnostic, formative and summative. To collect the data, we used a questionnaire with 15 open questions being answered by the teachers themselves and delivered later not only for analysis but also for systematization. The results indicated that the teachers who took part in the survey recognize that to the extent that they evaluate their own students, they realize whether their goals are being achieved, and can reshape their practice to meet the needs of the class and consequently contribute to a better learning. In relation to the practices used to evaluate, they are well diversified, including: participation, performance of activities, varieties of exercises, exams, questions, text production, reports of students, recreational activities, work in pairs and singles, etc..
\end{abstract}

KEYWORDS: Evaluation. Teaching practice. Teaching and learning. Elementary school.

\section{REFERÊNCIAS}

BOTH, I. J. Avaliação planejada, aprendizagem consentida: a filosofia do conhecimento. 1.ed. Curitiba: IBPEX, 2007.

BRASIL. Ministério da Educação. Lei de Diretrizes e Bases da Educação Nacional. Lei n. 9.394/96. Brasília: MEC, 1996. 
Nacionais: introdução. Brasília, DF: Senado Federal, 1997.

CARVALHO, M. E. P. Modos de educação, gênero e relações escola-família. Cadernos de Pesquisa, São Paulo, v.34, n.121, jan./abr. 2004. Disponível em: <http://www.scielo.br/pdf/cp/v34n121/a03n121.pdf>. Acesso em: 21 out. 2011.

DEMO, P. Avaliação qualitativa. 6.ed. Campinas: Autores Associados, 1999.

FRANCO, M. L. P. B. Subsídios para uma reflexão teórica acerca da prática avaliativa. Séries Ideias, São Paulo, n.8, p.119-126, 1998.

GIL, A. C. Didática do ensino superior. São Paulo: Atlas, 2006.

GONÇALVES, J. P. et al. A percepção de crianças e adultos sobre o medo de avaliação. In: II JORNADA NACIONAL DE EDUCAÇÃO DE NAVIRAÍ, 2010, Naviraí. Anais... Naviraí, 2010. p.129-137.

HADJI, C. Avaliação desmistificada. Tradução de Patrícia C. Ramos. Porto Alegre: ARTMED, 2001.

HAYDT, R. C. C. Avaliação do processo ensino-aprendizagem. São Paulo: Ática, 1988.

HOFFMANN, J. Avaliação mediadora: uma prática em construção da pré-escola à universidade. 7.ed. Porto Alegre: Mediação, 2005.

KRAEMER, M. E. P. Avaliação da aprendizagem como construção do saber. 2006. Disponível em:

<http://www.gestaouniversitaria.com.br/index.php?option=com_content\&view=article \&id=344:avaliacao-da-aprendizagem-como-construcao-dosaber\&catid=72:104\&Itemid=21 >. Acesso em: 10 abr. 2012.

LIBÂNEO, J. C. Didática. 2.ed. São Paulo: Cortez, 1994.

LUCKESI, C. C. Avaliação da aprendizagem escolar. 4.ed. São Paulo: Cortez, 1996.

MINAYO, M. C. S. Pesquisa social: teoria, método e criatividade. 22.ed. Rio de Janeiro: Vozes, 2003.

MOISÉS, R. L. G., MOORI, G. R. Coleta de dados para a pesquisa acadêmica: um estudo sobre a elaboração, a validação e a aplicação eletrônica de questionário. 2007 Disponível em:

<http://www.abepro.org.br/biblioteca/ENEGEP2007_TR660483_9457.pdf>. Acesso em: 10 abr. 2012.

PERRENOUD, P. Avaliação: da excelência a regulação da aprendizagem. Tradução de Patrícia C. Ramos. Porto Alegre: ARTMED, 1999. 
SANTOS, S. C. et al. Avaliação no mundo hodierno: um intervir sobre a produção do conhecimento. Revista Iberoamericana de Educación, Santa Maria, n.53, p.1-10, jun. 2010.

SOBRINHO, J. D. Construindo o campo e a crítica: o debate. In: FREITAS, L.C. (Org.) Avaliação: construindo o campo e a crítica. Florianópolis: Insular, 2002. p.167.

TYLER, R. Princípios básicos de currículo e ensino. Porto Alegre: Artes Médicas, 1975.

VIANNA, H. M. Testes em educação. Rio de Janeiro: Fename, 2003. 